\title{
Hydration and Chronic Kidney Disease Progression: A Critical Review of the Evidence
}

\author{
William F. Clark ${ }^{a}$ Jessica M. Sontrop ${ }^{b}$ Shi-Han Huang ${ }^{a}$ Louise Moist ${ }^{a} b$ \\ Nadine Bouby ${ }^{c, d}$ Lise Bankir ${ }^{c, d}$ \\ ${ }^{a}$ Division of Nephrology, Department of Medicine, London Health Sciences Centre, and ${ }^{\mathrm{b}}$ Department of \\ Epidemiology and Biostatistics, Western University, London, Ont., Canada; ' INSERM Unit 1138-E2 Centre de \\ Recherche des Cordeliers, The Cordeliers Research Center (CRC) and d The Cordeliers Research Center (CRC), \\ Université Pierre et Marie Curie, Paris, France
}

\section{Key Words}

Water $\cdot$ Chronic kidney disease $\cdot$ Vasopressin $\cdot$ Copeptin

\begin{abstract}
We performed a comprehensive literature review to examine evidence on the effects of hydration on the kidney. By reducing vasopressin secretion, increasing water intake may have a beneficial effect on renal function in patients with all forms of chronic kidney disease (CKD) and in those at risk of CKD. This potential benefit may be greater when the kidney is still able to concentrate urine (high fluid intake is contraindicated in dialysis-dependent patients). Increasing water intake is a well-accepted method for preventing renal calculi, and current evidence suggests that recurrent dehydration and heat stress from extreme occupational conditions is the most probable cause of an ongoing CKD epidemic in Mesoamerica. In polycystic kidney disease (PKD), increased water intake has been shown to slow renal cyst growth in animals via direct vasopressin suppression, and pharmacologic blockade of renal vasopressin-V2 receptors has been shown to slow cyst growth in patients. However, larger clinical trials are needed to determine if supplemental water can safely slow the loss of kidney function in PKD patients.
\end{abstract}

\section{KARGER}

E-Mail karger@karger.com

www.karger.com/ajn

\section{Introduction}

Regulation of body fluid volume by the kidney was pivotal in the emergence of life forms from water to land. This control of water homeostasis, which largely depends on the antidiuretic hormone vasopressin, is an adaptive response essential for a terrestrial habitat. In the short term, it ensures an intra-vascular volume for such vital issues as the flight and fight reaction [1]. However, in the long term, vasopressin effects on kidney function and blood pressure may have negative consequences by increasing renal plasma flow, glomerular filtration rate (GFR) and urinary albumin leakage (the hallmarks of progressive kidney injury) [2-4]. We examined evidence for the effects of hydration on plasma levels of vasopressin and kidney function and in patients with chronic kidney disease $(\mathrm{CKD})$, diabetic nephropathy, Mesoamerican

The Cordeliers Research Center (CRC) was established in 2007 under the direction and under the impetus of Professor Hervé Fridman, specialist in clinical immunology, under the joint supervision of the $\mathrm{Na}$ tional Institute of Health and medical research (INSERM), University Pierre et Marie Curie, University Paris Descartes and in connection with the National Centre for Scientific research (CNRS), Paris Diderot University and the Ecole Pratique des Hautes Etudes. 
nephropathy, nephrolithiasis, autosomal dominant polycystic kidney disease (ADPKD) and end-stage kidney disease.

\section{Search Strategy}

A search for relevant articles was performed in MEDLINE and PubMed without any time limits. The search terms used were the following: fluid intake, water intake, water prescription, hydration, chronic kidney disease, CKD, renal failure, kidney failure, end-stage renal disease, renal transplantation, kidney transplantation, vasopressin, kidney function, estimated glomerular filtration rate, eGFR, diabetic nephropathy, Mesoamerican nephropathy, nephrolithiasis, kidney stones and autosomal dominant polycystic kidney disease. We also searched the reference lists of identified articles for additional relevant articles. All papers reviewed were English language full-text papers.

\section{Biologic Rationale: An Overview of Animal Studies with Reference to Potential Mechanisms via Vasopressin}

Vasopressin, a small peptide (9 amino acids), is a very old hormone. Similar peptides exist in worms, mollusks and insects as well as in lower vertebrates. In humans, its antidiuretic activity is mainly due to its action on the permeability to water mediated by the V2 receptors (V2Rs) in renal collecting ducts. The vascular organization surrounding the specialized loop-shaped nephrons favors the accumulation of concentrated solutes in the renal medulla. Since the collecting ducts traverse the whole cortex and medulla, water can be extracted from the luminal fluid by osmotic driving force, concentrating urinary solutes and markedly reducing the urinary flow rate. In the cortical and outer medullary collecting ducts, vasopressin stimulates sodium reabsorption through the sodium channel $\mathrm{ENaC}$. This allows more water to be reabsorbed, but at the expense of a reduced sodium excretion [5]. Vasopressin also increases the permeability to urea in the terminal inner medullary collecting ducts by activating the facilitated urea transporter UT-A1. This ensures the delivery of concentrated urea to the inner medullary interstitium, which can be trapped there by countercurrent exchanges between the ascending and descending vasa recta $[6,7]$. This is an important feature of the concentrating mechanism because keeping a high urea concentration at the tip of the papilla allows the kidney to concentrate urea in the urine in humans up to 100 times more than in the blood. This water economy occurs at the expense of a lesser efficiency in urea excretion (from about $60 \%$ at high urine flow rates to about $25-30 \%$ at low urine flow rates) $[8,9]$.

When urine concentration is stimulated by a selective agonist of vasopressin V2Rs (dDAVP) in conscious rats, GFR (measured by inulin clearance) is enhanced, and the kidney hypertrophied; conversely, GFR is decreased when vasopressin secretion is reduced by a chronic increase in water intake (fig. 1a) [10]. An influence of urine concentration on GFR was also observed in 12 healthy humans studied twice with either high or low hydration at a 2-week interval in random order. GFR was higher for every participant in the low hydration protocol (fig. 1b) [11]. Urinary albumin excretion is dose-dependently and reversibly increased in normal rats by chronic dDAVP infusion. In healthy humans, dDAVP infusion for $20 \mathrm{~min}$ also increased albuminuria over the next $2 \mathrm{~h}$ [12]. These studies show that the water economy mediated by vasopressin V2Rs is responsible for a significant hyperfiltration with increased urinary albumin excretion (in rats and humans) and kidney hypertrophy (rats) features similar to those induced by a high-protein diet $[13,14]$. In humans, ingestion of a protein-rich meal induces an acute rise in vasopressin secretion and urine osmolality [3], and chronic high protein intake results in higher vasopressin plasma concentrations $[4,5]$. Hyperfiltration is an adaptive response that limits the rise in plasma urea induced by protein intake or by the lesser efficiency of urea excretion in concentrated urine [6,7]. This adaptation may become deleterious in the long term, especially if kidney function is already altered $[6,8]$, as explained below. For this reason, it may be appropriate to reduce protein intake (or ingest smaller fractions) in order to regularize vasopressin secretion.

Bankir et al. [8] hypothesized that a high urine concentration would have the same adverse effects as a highprotein diet. Experiments conducted in rats with 5/6 nephrectomy showed the possible benefit of an increased fluid intake in CKD. Daily water intake was increased 3 -fold by providing food in a water-rich agar gel that reduced vasopressin secretion and urine osmolarity; this induced a significant reduction in proteinuria, kidney hypertrophy, glomerular lesions, interstitial injury and mortality, compared with 5/6 nephrectomized rats fed dry food (fig. 2) [15]. To determine if vasopressin also played a role in the hyperfiltration of diabetes mellitus (DM) and in diabetic nephropathy, DM was induced by streptozotocin in Brattleboro rats with diabetes insipidus (DI) due to a single point deletion in the vasopressin gene 


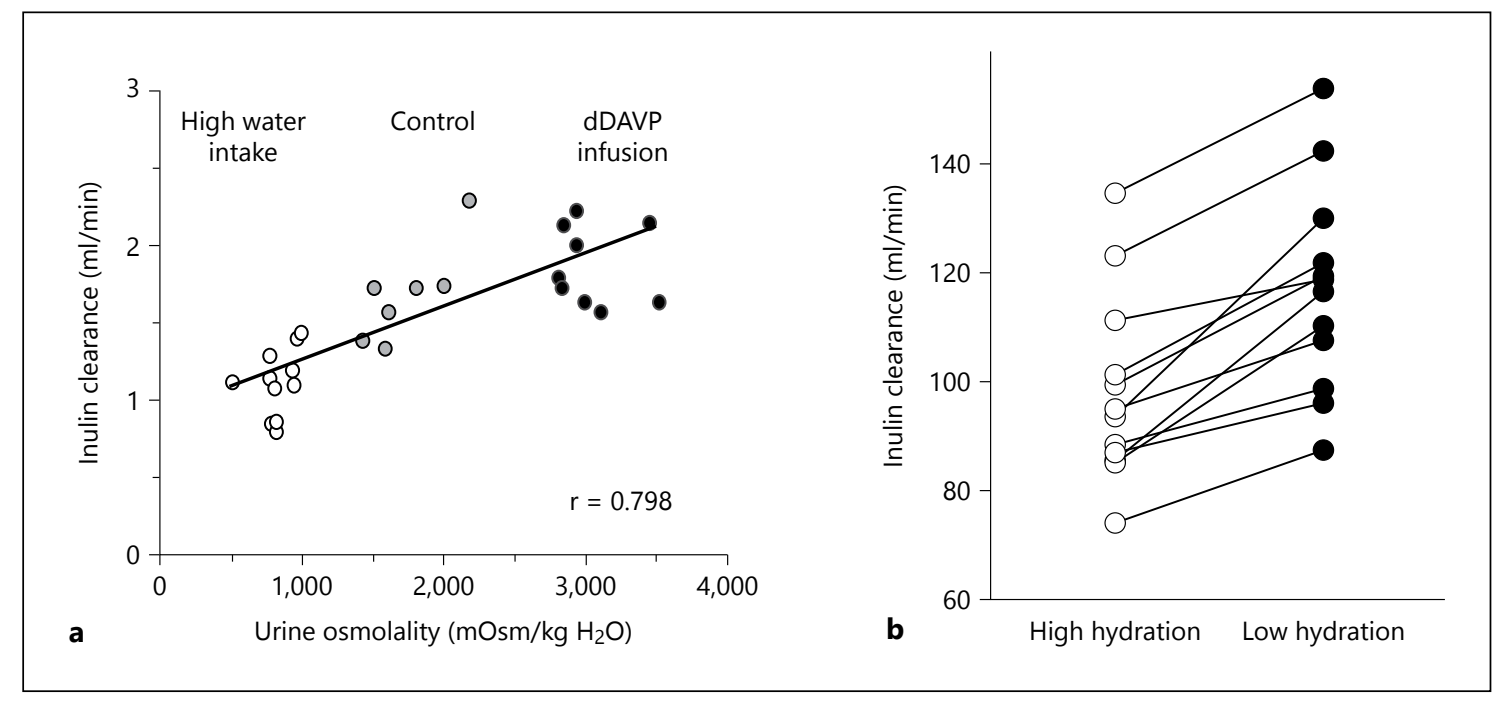

Fig. 1. Influence of urine concentration in normal rats and healthy subjects. a Urine osmolality in normal rats was either increased (by dDAVP infusion) or decreased (by providing extra drinking water in a gel food) for 1 week. GFR was measured as inulin clearance (inulin infused continuously through osmotic minipumps) with $2 \times 24$-hour urine collection. Each point represents one rat. GFR was positively and significantly correlated with the intensity of urine concentration. b GFR was measured as inulin clearance in healthy volunteers on 2 separate occasions in random order, during which the subjects were submitted to either a high or a low hydration ( 4.0 or $0.5 \mathrm{ml} / \mathrm{kg}$ body weight every $30 \mathrm{~min}$, respectively). In every subject, GFR was higher during the low hydration (with presumably high AVP) than the high hydration condition (with presumably low AVP). Adapted from Bouby et al. [10] and Anastasio et al. [11] for $\mathbf{a}$ and $\mathbf{b}$, respectively.

may also contribute to the lower sodium concentration at the macula densa.

In ADPKD, vasopressin may have the same adverse effects as in all kidney diseases (as explained above). In addition, it also exerts a direct adverse effect by stimulating cAMP formation (as second messenger) in its target cells in the collecting ducts. A number of studies in animal models and human cystic tissue in vitro have shown that cAMP aggravates the deterioration of kidney function by stimulating the secretion of cyst fluid and cyst enlargement [19]. For example, when rats with genetic PKD are crossed with Brattleboro rats with DI (unable to secrete vasopressin), they do not develop the cystic phenotype, unless they are infused with the V2R agonist dDAVP [20]. A recent clinical trial has shown the benefits of antagonizing vasopressin's antidiuretic action in patients with ADPKD and well-preserved renal function [21].

The results presented above suggest that reducing vasopressin secretion by increasing water intake or inhibiting vasopressin's V2R-mediated actions by selective vasopressin antagonists $[22,23]$ may benefit patients with all forms of CKD or those at risk of developing CKD. The benefit should be greater when the kidney is still able to concentrate urine [8]. 


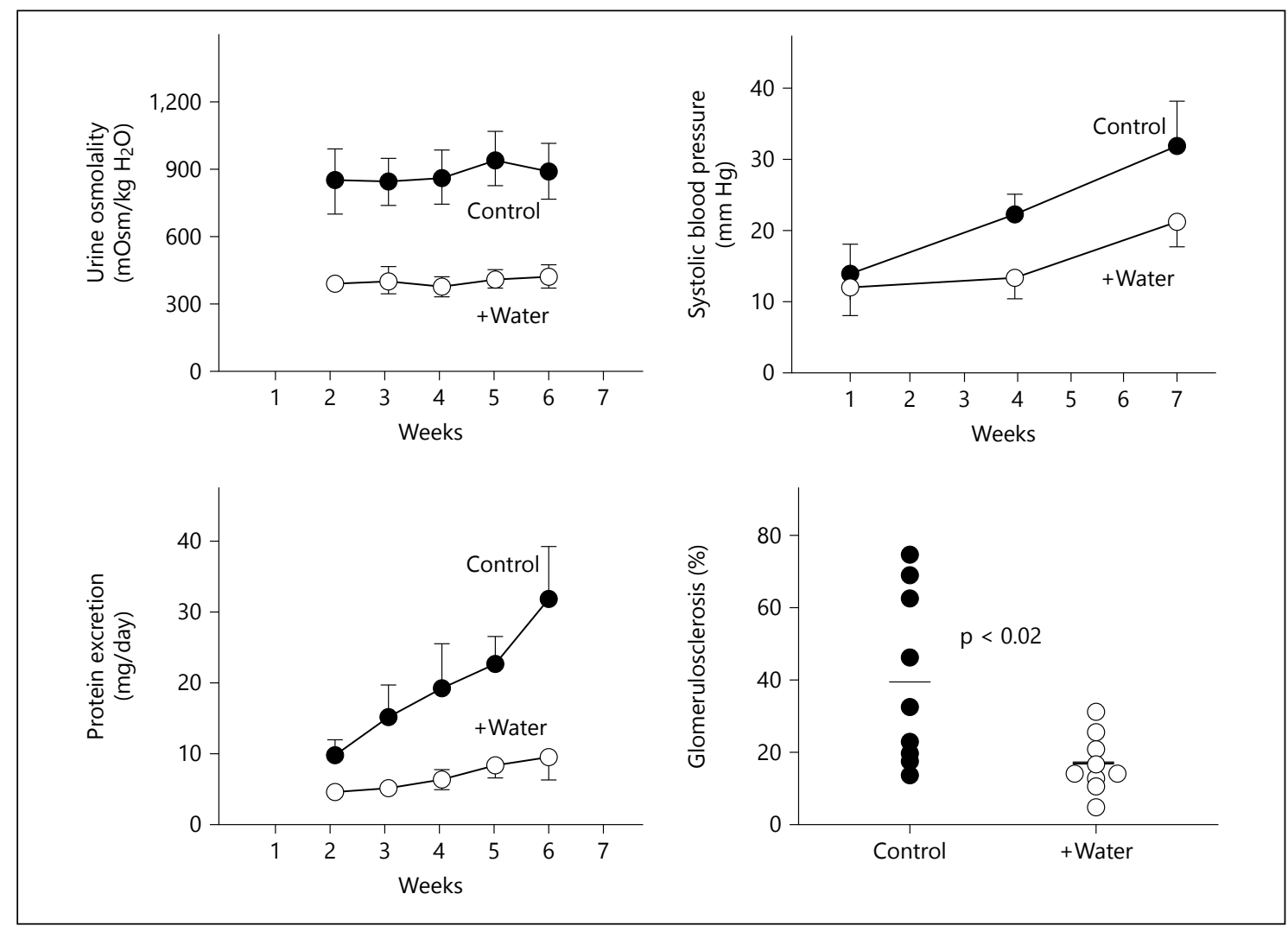

Fig. 2. Influence of urine concentration on urinary protein excretion, blood pressure and glomerulosclerosis in rats with CKD induced by $5 / 6$ nephrectomy. Both groups had drinking water ad libitum. In addition, urine osmolality was reduced in the ' + water' group by providing the daily food in a water-rich agar gel (note however, that care was taken to adapt the extra water supply so as

The Role of Hydration in CKD, Diabetic Nephropathy, Mesoamerican Nephropathy, Nephrolithiasis, ADPKD and End-Stage Kidney Disease

\section{Chronic Kidney Disease}

Currently, 6 observational studies in humans have reported on the potential role of water and/or fluid intake in CKD [24-29]. Superficially, these studies appear in conflict; however, critical analysis suggests a differing view. In a post-hoc analysis of 581 patients in the Modification of Diet in Renal Disease study with an eGFR between 25 and $55 \mathrm{ml} /$ $\mathrm{min} / 1.73 \mathrm{~m}^{2}$, higher urine volume was associated with faster eGFR decline [24]. However, the statistical association between rising creatinine and urine volume was no longer seen when participant use of diuretics and antihypertensive medication was controlled for. Because diuretics can increase urine flow and many anti-hypertensives decrease renal blood flow, their combined use may explain the statisti- not to induce the production of hypo-osmotic urine). Increased water intake and the resulting lower vasopressin secretion and lower urine concentration reduced the rise in urinary protein excretion, systolic blood pressure and glomerulosclerosis seen in the control group. Adapted from Bouby et al. [15]. cal association between higher creatinine and urine volume that was observed in this study. This small, observational study underlines the need to adjust for as many baseline variables as possible before attributing causality.

Two studies of the same population from the Blue Mountains region in Australia reached different conclusions on the association between self-reported fluid intake (excluding plain water) and CKD $[26,28]$. The first study consisted of 2 cross-sectional surveys including 2,744 and 2,476 participants who completed a food frequency questionnaire and had baseline measurements of eGFR [26]. The second study included 1,207 of the 2,744 participants in the first survey who also had measurements of eGFR approximately 10 years later [28]. While the cross-sectional analyses found an inverse association between baseline self-reported fluid intake and prevalence of $\mathrm{CKD}$, in the longitudinal analyses in the smaller sample, fluid intake at baseline was not associated with 


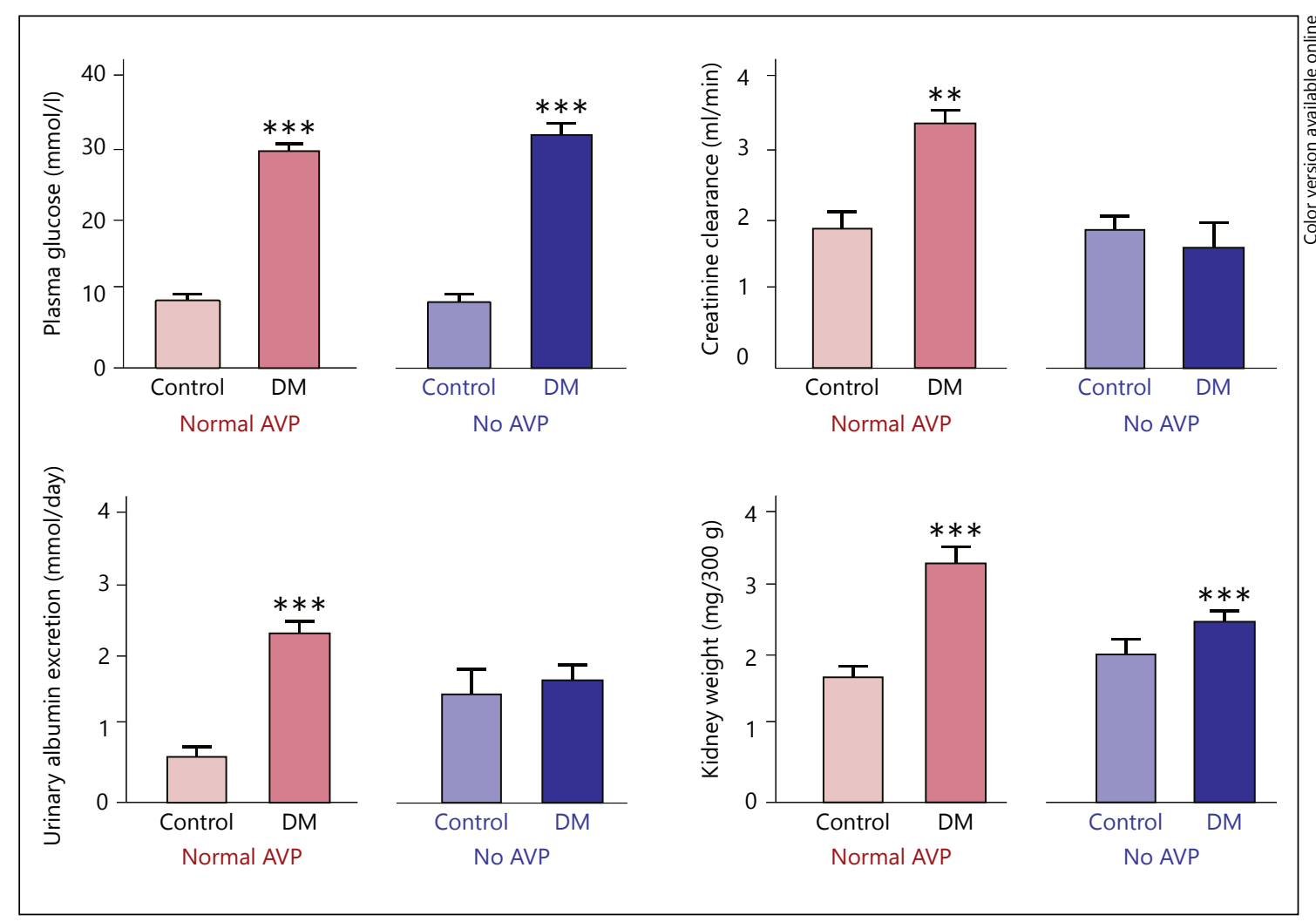

Fig. 3. Influence of urine concentration on the early manifestations of diabetic nephropathy. DM was induced by an injection of streptozotocin in Brattleboro rats that cannot secrete vasopressin (no AVP) and in control Long Evans rats (normal AVP). Sham injected rats served as controls. Although glycemia rose to the same ex- tent in the 2 strains of rats, the rise in creatinine clearance and urinary albumin excretion that were observed in control rats did not occur in the absence of AVP, and kidney hypertrophy was much less intense. Adapted from Bardoux et al. [16].
Fig. 4. A number of experimental studies in rats and a few observations in humans suggest that vasopressin increases GFR and albuminuria, thus inducing a vicious circle as suggested by Brenner [18] for a high protein diet. Adapted from Brenner [18].

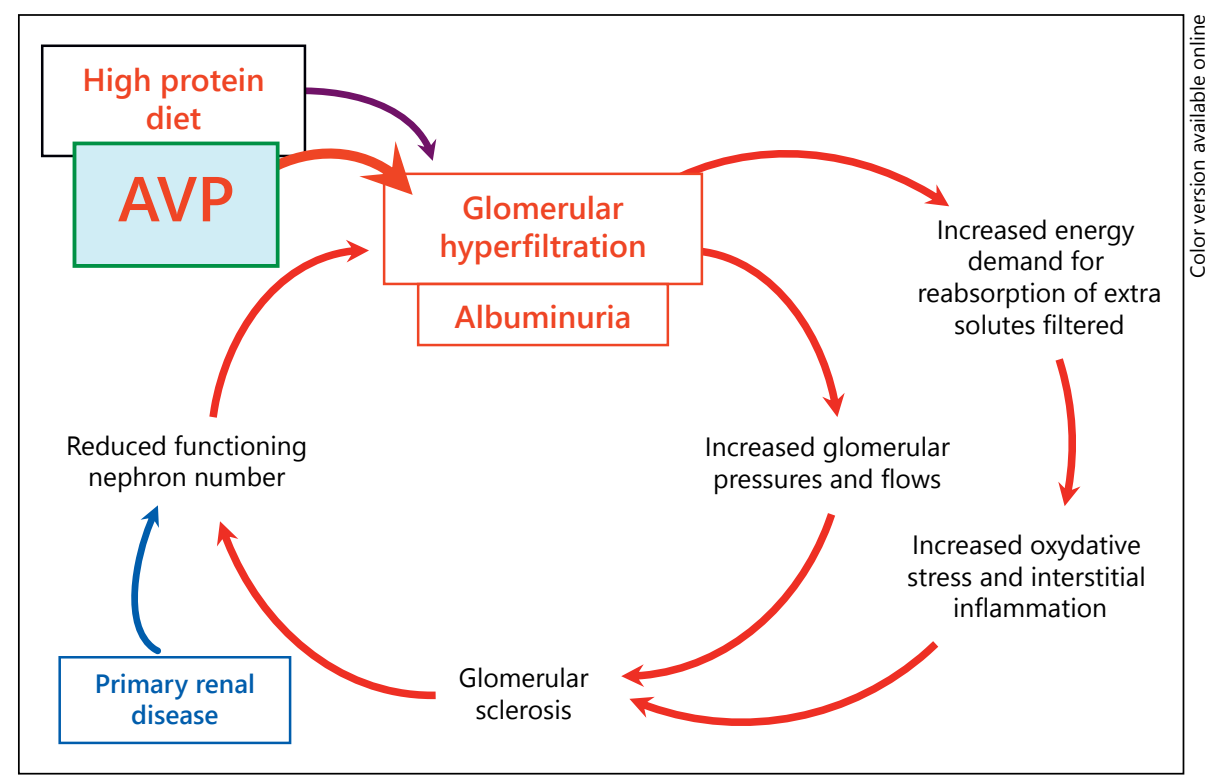


Fig. 5. Urine volume and risk for renal decline in the general population $(n=2,148)$. Adapted from Clark et al. [25]. * Multinomial logistic regression adjusted for age, sex, smoking, dipstick protein $\geq 1 \mathrm{~g} / \mathrm{l}$, medication use for hypertension (including diuretics), diabetes and cardiovascular disease. ${ }^{\dagger}$ Mild to moderate renal decline: eGER decline from baseline between 0 and $4.9 \%$. ${ }^{\ddagger}$ Rapid renal decline: eGER decline from baseline $\geq 5 \%$.

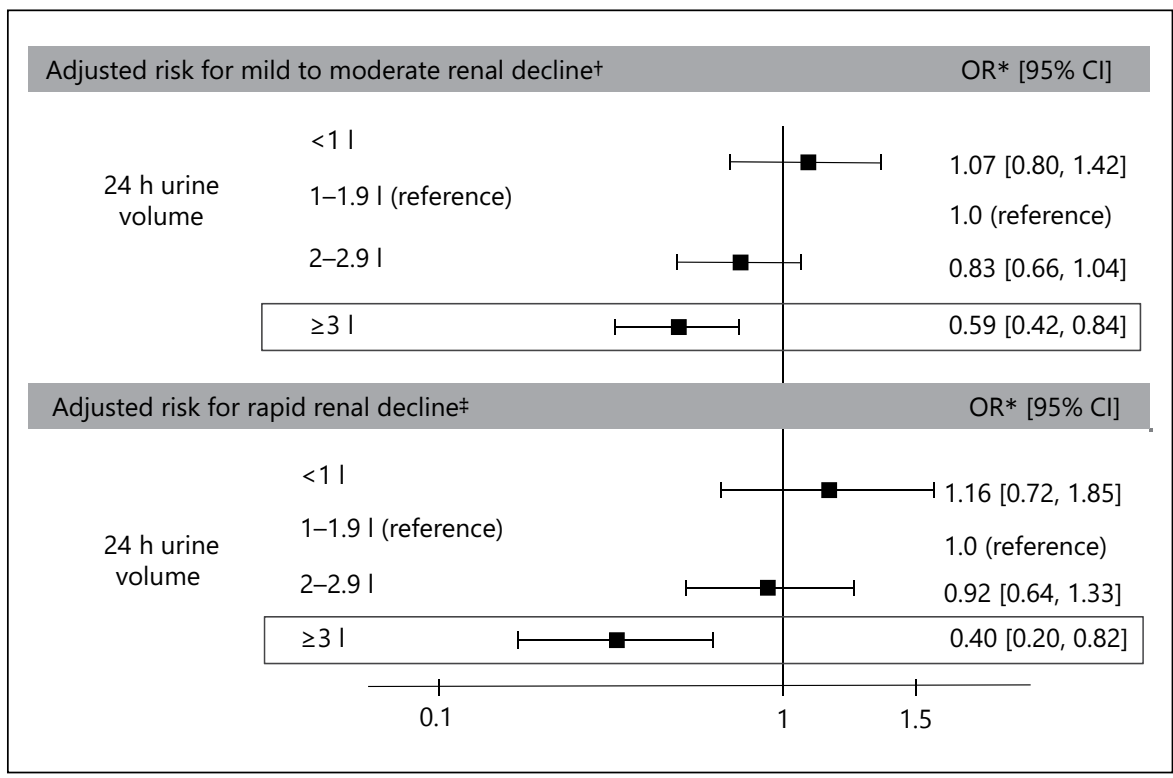

change in eGFR between baseline and last follow-up, although this analysis may have been under-powered. Similarly, a cross-sectional analysis of 3,427 participants in the US National Health and Nutrition Examination Survey, found that the prevalence of CKD (defined as an eGFR between 30 and $59 \mathrm{ml} / \mathrm{min} / 1.73 \mathrm{~m}^{2}$ ) was higher in those with the lowest total fluid intake (relative to the highest-intake group) [27]. Although the adjusted OR of 2.5 did not achieve statistical significance, when stratified by intake of plain water versus other beverages, CKD was significantly associated with a low intake of plain water (adjusted OR 2.4, 95\% CI 1.1-5.1) but not with other fluids. As noted by the authors, if increased hydration protects the kidney, any beneficial effects may be offset if total fluid consumption comes largely from sugar-sweetened beverages [30,31]. These observational studies are subject to selection bias and misclassification bias due to reliance on self-reported fluid intake.

In a 7-year prospective cohort study of 2,144 participants free of CKD at baseline, decline in kidney function was significantly slower in those with higher versus lower 24-hour urine volumes [25]. As shown in figure 5, those with the largest urine volumes ( $>3$ liters/day) were the least likely to demonstrate mild to moderate renal decline (1-4.9\%/year); adjusted OR 0.66 (95\% CI 0.460.94 ), or rapid renal decline ( $\geq 5 \% /$ year); adjusted OR 0.46 (95\% CI 0.23-0.92). These results were adjusted for medication use, including diuretics and risk factors for renal progression. The dose-response relationship of decreasing urine volume and decreasing kidney function in this fully adjusted prospective model suggests, but does not prove, causality due to an inability to control for unknown confounders. Finally, in a study 273 patients with CKD stages 1-4 [29], the risk of dialysis initiation increased with higher urine osmolality (OR 2.04, 95\% -CI 1.06-3.92) for each doubling of urine osmolality; adjusted for age, baseline creatinine clearance and diuretic use). The estimated adjusted cumulative incidence probabilities of dialysis were 15,24 and $34 \%$ in patients with baseline urine osmolality of $315,510,775 \mathrm{mOsm} / \mathrm{l}$. The authors concluded that urine osmolality in $\mathrm{CKD}$ was a potential modifiable risk factor by provision of supplemental water.

\section{Mesoamerican Nephropathy}

Since 2002, a startling excess of CKD has been documented in Central America and Southern Mexico, a phenomenon now termed Mesoamerican nephropathy [3237]. Rates of CKD in this region are 13-15 times higher than in age-matched adults in the United States [38], and El Salvador currently has the highest mortality rate from kidney disease in the world [39]. Whereas CKD is typically a disease of the elderly, this Mesoamerican variant disproportionately affects young men and develops in the absence of traditional risk factors. Patients present with elevated serum creatinine, low-grade or no proteinuria and no known cause of kidney disease. Kidney biopsies show a progressive tubulointerstitial disease with tubular atrophy, fibrosis and some signs of glomerular ischemia [39]. 
This epidemic has a distinct occupational and geographical pattern. The highest rates of CKD are seen among agricultural workers in the hottest Pacific lowlands of Nicaragua and El Salvador, where the prevalence of CKD is $18 \%$ compared with $1 \%$ in communities at higher elevations [39]. Sugarcane is a predominant industry in the coastal lowlands, and it was initially suspected that pesticides used in sugarcane production might be implicated in this epidemic. However, when Peraza et al. [36] compared the kidney function of sugarcane workers in low altitude versus those in high altitude settings, lowland sugarcane workers were 10 times more likely to have elevated serum creatinine than highland workers (30\% (34 of 113 ) versus $3 \%$ ( 2 of 73 ), $\mathrm{p}<0.001$. Other theories advanced to explain this epidemic have included exposure to contaminated drinking water or alcohol, heavy metals or infectious agents such as leptospirosis; however, evidence to date does not support these theories [37, 40, 41].

\section{The Heat Stress Hypothesis}

Severe heat stress with accompanying water and solute loss (with repeated volume depletion) can cause ischemic kidney injury, even in healthy adults [42]. Many scientists now believe that the most probable cause of Mesoamerican nephropathy is recurrent dehydration and heat stress from extreme occupational conditions which causes subclinical kidney injury that leads to permanent kidney damage over time [37, 42-44]. As described in recent field studies, sugarcane harvesting involves 4-6 h of heavy lifting in extremely hot conditions (temperatures often exceed $35^{\circ} \mathrm{C}$ in the coastal lowlands), and workers typically lose $2.6 \mathrm{~kg}$ in body weight after a day of harvesting [42, 45-47]. Further studies have shown significant increases in levels of urinary kidney injury biomarkers (including neutrophil gelatinase-associated lipocalin and interleukin 18) in field workers compared with non-field workers before and after the harvest season $[43,44]$. There is some evidence that hydrating with electrolyte solutions may protect against kidney injury among individuals working in strenuous jobs in hot environments; however, this has yet to be tested in a clinical trial $[43,44]$.

Whether heat stress causes CKD directly or in combination with other factors is uncertain. Some hypothesize that the nephrotoxic effect of heat stress and dehydration may be compounded by rehydrating with high-fructose fluids (which may induce renal injury by a polyol fructinase mechanism) [41, 48, 49] or by concurrent use of non-steroidal anti-inflammatory drugs or other nephrotoxic drugs [47]. The possibility that heat stress may increase the risk of acute kidney injury and CKD has

Hydration and CKD Progression:

A Critical Review of the Evidence global implications - occupational heat stress may also explain an excess of CKD in Sri Lanka, India and Brazil [50-52]. Scientists are now examining whether extreme heat affects renal outcomes in vulnerable populations in Australia, Europe and the United States [53-58].

In general, these observations suggest that higher water intake may preserve renal function; however, it remains unclear whether supplemental water can benefit patients with CKD. Because urine concentrating capacity is reduced as renal function declines, some patients with CKD will have a high 24-hour urine volume but actually be (slightly) volume depleted with a high vasopressin concentration, which makes it difficult to isolate the causal effects in observational studies. A randomized controlled trial is needed to definitively answer this question. In preparation for a larger RCT, we conducted a 6-week pilot trial to examine the safety and feasibility of asking adult patients with CKD to increase water intake. In this pilot trial, we randomly assigned 28 patients with stage 3 CKD to a hydration or control group $(2: 1)$. The hydration group was instructed to increase their water intake by 1.0 or 1.5 liters/day depending on sex, weight and 24-hour urine osmolality (in addition to usual fluid intake) for 6 weeks. The control group carried on with their usual intake. We advised a gradual increase in water intake over 2 weeks. During week 1, we instructed participants to consume 1 cup of water at breakfast, lunch and dinner, and during week 2 , the full amount according to weight, sex and urine osmolality (details available in BMJ Open $[59,60])$. Briefly, in the hydration group, 24-hour urine volume increased by 0.7 liters $(\mathrm{p}=0.01)$, while decreasing by 0.3 liters in the control group $(\mathrm{p}=0.07)$. Copeptin (a surrogate marker of vasopressin) decreased by $3.6 \mathrm{pmol} / \mathrm{l}$, from 15.0 to $10.8 \mathrm{pmol} / \mathrm{l}(\mathrm{p}=0.005)$, while remaining stable among controls at $19 \mathrm{pmol} / \mathrm{l}(\mathrm{p}=0.76)$. Median urine osmolality at baseline was $430 \mathrm{mOsm} / \mathrm{kg}$ and $393 \mathrm{mOsm} /$ $\mathrm{kg}$ in the hydration and control groups, respectively, and did not change significantly in either group over 6 weeks. No significant changes in electrolyte composition or quality of life were observed. A larger randomized controlled trial (currently underway; $\mathrm{n}=700$ ) will examine whether increased fluid intake can slow renal decline and decrease copeptin concentrations over 1 year of followup (ClinicalTrials.gov NCT0176687).

\section{Diabetic Nephropathy}

A growing body of evidence suggests that supplemental water may prevent or slow diabetic nephropathy; however, no clinical trials have been conducted to date. Studies in diabetic rats have shown that (1) a genetic deficiency of 
vasopressin prevents hyperfiltration and reduces proteinuria and (2) vasopressin V2R antagonists block albuminuria $[16,17]$. In humans, a vasopressin V2R agonist decreases urine flow rate, increases urine electrolyte concentration and triples albumin excretion rates [12]. Several epidemiologic studies have noted an association between copeptin levels (a surrogate marker of vasopressin) and microalbuminuria, the hallmark of diabetic nephropathy $[61,62]$. Furthermore, in a study of 3,000 participants with diabetic nephropathy, albuminuria and plasma copeptin were independently associated with renal decline and endstage renal disease [63]. Finally, in a study of 1,328 type II diabetics, higher plasma copeptin concentration was associated with greater albuminuria and eGFR decline over 6.5 years of follow-up [64]. These studies provide the rationale to examine whether diabetic nephropathy can be prevented or slowed by reducing vasopressin activity through increased water intake or a V2R antagonist.

\section{Nephrolithiasis}

Increasing water intake is a well-accepted method for reducing the recurrence of kidney stones. The American Urological Association and American College of Physicians both recommend increasing water intake to achieve a urine volume of at least 2.0-2.5 liters/day to prevent recurrent kidney stones $[65,66]$. Higher water intake is thought to protect against stone formation by increasing urine volume and flow rate, which lowers the supersaturation of calcium oxalate, calcium phosphate and uric acid $[65,67,68]$. Of note, several studies have demonstrated effect modification by fluid type, where high intake of sugar-sweetened beverages is associated with an increased risk for stone formation, possibly due to the high fructose content, which has been shown to increase urinary excretion of calcium, oxalate and uric acid [6972].

\section{Autosomal Dominant Polycystic Kidney Disease}

ADPKD is the most common inherited kidney disease leading to end-stage kidney disease. ADPKD is characterized by the gradual expansion of kidney cysts, with enlargement of the kidneys, measured by the total kidney volume (TKV). Kidney enlargement is continuous and quantifiable by MRI and is associated with a more rapid loss of kidney function [73]. Kidney volumes above 1,500 $\mathrm{ml}$, at baseline follow-up, are associated with a declining GFR of approximately $5 \mathrm{ml} / \mathrm{min} /$ year, with TKV increasing more in patients with $A D P K D 1$ compared to those with $A D P K D 2$ [73]. In a more recent study, baseline height adjusted $\mathrm{TKV} \geq 600 \mathrm{ml} / \mathrm{m}$, in patients with preserved kid- ney function, predicted the risk of progression to CKD (GFR $>60 \mathrm{ml} / \mathrm{min} / 1.73 \mathrm{~m}^{2}$ ) over 1 year of follow-up [74].

In ADPKD, renal cysts originate from the epithelia of the nephrons and renal collecting system and are lined by a single layer of cells that have higher rates of cellular proliferation. Abnormalities in gene expression, cell polarity, fluid secretion, apoptosis and extracellular matrix have been described in ADPKD [75]. Arginine vasopressin (AVP) stimulates the production of c-AMP in the distal and collecting tubules by binding to AVP-V2Rs. Blocking the effects of AVP and thereby decreasing c-AMP levels by means of high water intake or genetic elimination of vasopressin or use of an AVP-V2R antagonist attenuates kidney enlargement and kidney functional deterioration in animal models $[20,76]$. A large randomized control trial of Tolvaptan $(\mathrm{n}=1,445)$, an AVP-V2R antagonist, reported a significant slowing in the increase in TKV and decline in kidney function in patients with ADPKD [21]. It has been hypothesized that ingestion of supplemental water sufficient to cause a water diuresis would lower the plasma level of AVP, accomplishing the same renal action as blocking the V2Rs [77, 78]. Advantages and disadvantages of strategies to reduce the impact of vasopressin on kidney function are summarized in table 1 [8]. In the CRISP study, baseline copeptin levels, a surrogate for AVP levels, were independently associated with disease progression in early ADPKD [79]. Additionally, a recent study in rodents shows a central role for AVP and cAMP in promoting kidney enlargement and reducing renal function in PKD [76]. Water intake was increased in a rat model of PKD to physiologically suppress AVP and its effect on renal morphology, cellular mechanism and function. In these rats, increased water intake reduced urinary AVP excretion, and urine osmolality fell below $290 \mathrm{mOsmol} / \mathrm{kg} \mathrm{H}_{2} \mathrm{O}$. High water intake was associated with reduced renal expression of AVP V2Rs, reduced kidney/body weight ratio and improved renal function. A pilot clinical study recently determined the amount of additional water needed to achieve a urine osmolality target based on the urine osmolar excretion in ADPKD patients with normal renal function [77]. During the 2-week study, urine volume and osmolality were measured, and additional water intake was adjusted in order to achieve a urine osmolality goal of $285 \pm 45 \mathrm{mOsm} / \mathrm{kg} \mathrm{H}_{2} \mathrm{O}$. These adjustments resulted in water intake in the range of $2,400-3,000 \mathrm{ml}$ per $24 \mathrm{~h}$. Although this study was of short duration, it did demonstrate that increasing water intake in ADPKD patients was feasible. A recent small study in ADPKD patients, comparing high versus 'free intake' of water reduced urine osmolality to 329 in the high and 523 
Table 1. Advantages and disadvantages of strategies to reduce the impact of vasopressin on kidney function (reproduced from Bankir et al. [8])

\begin{tabular}{|c|c|c|}
\hline Outcome & Increase fluid intake & V2R antagonist \\
\hline Patient behavior & Voluntary frequent drinking & Taking a pill \\
\hline Adherence to treatment & Poor (difficult to drink without thirst) & Good (easy) \\
\hline Plasma osmolality & Decreased & Increased \\
\hline Vasopressin secretion and plasma level & Decreased & Increased \\
\hline $\begin{array}{l}\text { Vasopressin effects mediated by other } \\
\text { receptors (V1aR and V1bR)* }\end{array}$ & Reduced & Enhanced \\
\hline Possible side effects & $\begin{array}{l}\text { Aversion to water, frequent need to } \\
\text { urinate, risk of hyponatraemia }\end{array}$ & $\begin{array}{l}\text { Thirst, frequent need to } \\
\text { urinate, risk of dehydration }\end{array}$ \\
\hline Financial costs & None & High \\
\hline
\end{tabular}

$\mathrm{mOsm} / \mathrm{kg} \mathrm{H} \mathrm{H}_{2} \mathrm{O}$ in the free water-intake group [80]. The high fluid-intake group had significantly lower copeptin levels compared with the control group; however, there was no significant difference in eGFR nor TKV at 1 year, as might be expected due to the small number of participants $(\mathrm{n}=34)$ and relatively short follow-up. Theoretically, it may be reasonable to recommend modestly increasing the amount of solute free water evenly through the day, for patients with ADPKD to decrease plasma AVP levels and mitigate the action of cAMP on cyst size and resultant loss of kidney function. Clearly larger RCTs are needed to determine if the role of supplemental water can safely slow the loss of kidney function in patients with ADPKD.

\section{End-Stage Kidney Disease}

Although increased hydration and reduced vasopressin secretion appear to slow renal progression in patients with CKD, over-hydration can be detrimental to patients with end-stage kidney disease [81]. When the kidneys fail, renal replacement therapy is required to remove toxins and fluid and negative consequences can result from chronic fluid overload and high fluid removal during dialysis $[82,83]$. Chronic fluid overload in dialysis patients can lead to hypertension and left ventricular hypertrophy, which is associated with cardiovascular morbidity and mortality [84]. Removing more than 2 liters during hemodialysis can also lead to myocardial stunning, which may increase the risk for cardiovascular morbidity and mortality $[85,86]$. To avoid this, both so- dium and fluid restriction in dialysis patients is recommended [87].

By contrast, 1 year after kidney transplantation, total body water is significantly reduced and the proportion of body fat is significantly increased relative to that during dialysis [88]. For this reason, some transplant centers recommend that recipients increase hydration after renal transplantation to slow renal progression. Studies have shown that a higher copeptin concentration is associated with faster renal decline after kidney transplantation [89]. However, the effect of increased hydration in kidney transplant recipients is unclear. Only a few small studies have examined the relationship between post-transplant hydration and allograft outcomes in transplant recipients. In 2 prospective observational studies by Gordon et al. [90, 91], 88 renal transplant recipients were recruited 2 months after they had received renal allografts and were followed for 12 months. Greater fluid intake was associated with improved graft function [91]; however, only $35 \%$ of prior participants reported drinking the recommended 3 liters of fluid daily [90].

The sub-study of the Angiontensin II Blockade for Chronic Allograft Nephropathy (ABCAN) trial $(n=153)$ hypothesized that increased fluid intake as ascertained by urine output may adversely affect graft outcome [92]. The $\mathrm{ABCAN}$ trial is a randomized controlled trial to assess the benefit of an angiotensin II blocker in preventing cortical interstitial fibrosis after renal transplantation in patients with serum creatinine level $<222 \mu \mathrm{mol} / \mathrm{l}(2.5 \mathrm{mg} / \mathrm{dl})$. In a post-hoc analysis, the study population was divided into 
3 groups based on their 24-hour urine volume at baseline: $1.73,1.73-2.56$ and $>2.56$ liters/day; however, no associations were seen with interstitial volume doubling or endstage kidney disease. In a small trial of pediatric renal transplant patients (20 each arm) [93], interactive water bottles were used to calculate personal hydration needs and to track fluid consumption throughout the day. While hydration status improved significantly in the water-bottle group, no differences in renal function were observed. Finally, in a small trial of renal transplant recipients randomized to drink 2 liters/day $(\mathrm{n}=33)$ versus 4 liters/day $(n=29)$, no difference in eGFR was seen after 12 months [94]. However, the absence of an association between urine volume and osmolality suggests low adherence to fluid intake intervention. Taken together, these studies are equivocal as to whether supplemental water intake is beneficial in kidney transplant recipients; however, most trials were underpowered or failed to demonstrate separation between groups in fluid intake. Larger sufficiently powered randomized control trials with objective and verifiable assessments of fluid intake and adherence are needed to assess the potential benefit of supplemental water in renal transplant populations.

\section{Conclusions}

By reducing vasopressin secretion, increasing water intake appears to have a beneficial effect on renal function in patients with all forms of CKD and in those at risk of $\mathrm{CKD}$. These potential benefits may be greater when the kidney is still able to concentrate urine. Several observational studies have reported positive associations between increased water intake (or high urine volume) and preservation of renal function, and high water intake is a wellaccepted method for preventing renal calculi. By contrast, high water intake is contraindicated in dialysis-dependent patients and the role of higher water intake in kidney transplant recipients is unclear. In $\mathrm{PKD}$, increased water intake has been shown to slow renal cyst growth in animals via direct vasopressin suppression, and pharmacologic blockade of renal vasopressin-V2Rs has been shown to slow cyst growth in patients. Taken together, these studies support the exploration of a potential therapeutic role for increased hydration in $\mathrm{CKD}$, diabetic nephropathy, Mesoamerican nephropathy, PKD and renal transplantation in well-designed randomized controlled trials.

\section{Funding}

This work was supported by Danone Research and the Program of Experimental Medicine, Western University, Canada. The study sponsors had no direct role in the conduct of this review or drafting of the manuscript.

\section{Disclosure Statement}

Dr. W.F. Clark and Dr. L. Moist have received consulting fees and/or honorarium and support to travel to meetings with Danone Research. Dr. W.F. Clark is currently conducting a randomized controlled trial funded by Danone Research. No other authors have relevant conflicts of interest to declare.

\section{References}

1 Sawyer WH, Munsick RA, van Dyke HB: Antidiuretic hormones. Circulation 1960;21: 1027-1037.

2 Torres VE: Vasopressin in chronic kidney disease: an elephant in the room? Kidney Int 2009;76:925-928.

3 Edwards RM, Trizna W, Kinter LB: Renal microvascular effects of vasopressin and vasopressin antagonists. Am J Physiol 1989;256(2 pt 2):F274-F278.

4 Perico N, Zoja C, Corna D, Rottoli D, Gaspari F, Haskell L, et al: V1/V2 Vasopressin receptor antagonism potentiates the renoprotection of renin-angiotensin system inhibition in rats with renal mass reduction. Kidney Int 2009;76:960-967.

5 Bankir L, Bichet DG, Bouby N: Vasopressin $\mathrm{V} 2$ receptors, $\mathrm{ENaC}$, and sodium reabsorption: a risk factor for hypertension? Am J Physiol Renal Physiol 2010;299:F917-F928.
6 Fenton RA: Urea transporters and renal function: lessons from knockout mice. Curr Opin Nephrol Hypertens 2008;17:513-518.

7 Yang B, Bankir L: Urea and urine concentrating ability: new insights from studies in mice. Am J Physiol Renal Physiol 2005;288:F881F896.

8 Bankir L, Bouby N, Ritz E: Vasopressin: a novel target for the prevention and retardation of kidney disease? Nat Rev Nephrol 2013; 9:223-239.

9 Bankir L, Bouby N, Trinh-Trang-Tan MM, Ahloulay M, Promeneur D: Direct and indirect cost of urea excretion. Kidney Int 1996; 49:1598-1607.

10 Bouby N, Ahloulay M, Nsegbe E, Déchaux M, Schmitt F, Bankir L: Vasopressin increases glomerular filtration rate in conscious rats through its antidiuretic action. J Am Soc Nephrol 1996;7:842-851.
11 Anastasio P, Cirillo M, Spitali L, Frangiosa A, Pollastro RM, De Santo NG: Level of hydration and renal function in healthy humans. Kidney Int 2001;60:748-756.

12 Bardoux P, Bichet DG, Martin H, Gallois Y, Marre M, Arthus MF, et al: Vasopressin increases urinary albumin excretion in rats and humans: involvement of $\mathrm{V} 2$ receptors and the renin-angiotensin system. Nephrol Dial Transplant 2003;18:497-506.

13 Bouby N, Trinh-Trang-Tan MM, Coutaud C, Bankir L: Vasopressin is involved in renal effects of high-protein diet: study in homozygous Brattleboro rats. Am J Physiol 1991; 260(1 pt 2):F96-F100.

14 Bankir L, Kriz W: Adaptation of the kidney to protein intake and to urine concentrating activity: similar consequences in health and CRF. Kidney Int 1995;47:7-24. 
15 Bouby N, Bachmann S, Bichet D, Bankir L: Effect of water intake on the progression of chronic renal failure in the 5/6 nephrectomized rat. Am J Physiol 1990;258(4 pt 2):F973-F979.

16 Bardoux P, Martin H, Ahloulay M, Schmitt F, Bouby N, Trinh-Trang-Tan MM, et al: Vasopressin contributes to hyperfiltration, albuminuria, and renal hypertrophy in diabetes mellitus: study in vasopressin-deficient Brattleboro rats. Proc Natl Acad Sci U S A 1999; 96:10397-10402.

17 Bardoux P, Bruneval P, Heudes D, Bouby N, Bankir L: Diabetes-induced albuminuria: role of antidiuretic hormone as revealed by chronic V2 receptor antagonism in rats. Nephrol Dial Transplant 2003;18:1755-1763.

18 Brenner BM: Nephron adaptation to renal injury or ablation. Am J Physiol 1985;249:F324F337.

19 Devuyst O, Torres VE: Osmoregulation, vasopressin, and cAMP signaling in autosomal dominant polycystic kidney disease. Curr Opin Nephrol Hypertens 2013;22:459-470.

20 Wang X, Wu Y, Ward CJ, Harris PC, Torres VE: Vasopressin directly regulates cyst growth in polycystic kidney disease. J Am Soc Nephrol 2008;19:102-108.

21 Torres VE, Chapman AB, Devuyst O, Gansevoort RT, Grantham JJ, Higashihara E, et al: Tolvaptan in patients with autosomal dominant polycystic kidney disease. N Engl J Med 2012:367:2407-2418.

22 Serradeil-Le Gal C, Wagnon J, Valette G, Garcia G, Pascal M, Maffrand JP, et al: Nonpeptide vasopressin receptor antagonists: development of selective and orally active V1a, V2 and V1b receptor ligands. Prog Brain Res 2002;139:197-210.

23 Verbalis JG: AVP receptor antagonists as aquaretics: review and assessment of clinical data. Cleve Clin J Med 2006;73 (suppl 3):S24S33.

24 Hebert LA, Greene T, Levey A, Falkenhain ME, Klahr S: High urine volume and low urine osmolality are risk factors for faster progression of renal disease. Am J Kidney Dis 2003;41:962-971.

25 Clark WF, Sontrop JM, Macnab JJ, Suri RS, Moist L, Salvadori M, et al: Urine volume and change in estimated GFR in a communitybased cohort study. Clin J Am Soc Nephrol 2011;6:2634-2641.

26 Strippoli GF, Craig JC, Rochtchina E, Flood VM, Wang JJ, Mitchell P: Fluid and nutrient intake and risk of chronic kidney disease. Nephrology (Carlton) 2011;16:326-334.

27 Sontrop JM, Dixon SN, Garg AX, BuendiaJimenez I, Dohein O, Huang SH, et al: Association between water intake, chronic kidney disease, and cardiovascular disease: a crosssectional analysis of NHANES data. Am J Nephrol 2013;37:434-442.

28 Palmer SC, Wong G, Iff S, Yang J, Jayaswal V, Craig JC, Rochtchina E, Mitchell P, Wang JJ, Strippoli GF: Fluid intake and all-cause mortality, cardiovascular mortality and kidney function: a population-based longitudinal co- hort study. Nephrol Dial Transplant 2014;29: 1377-1384.

29 Plischke M, Kohl M, Bankir L, Shayganfar S, Handisurya A, Heinze G, et al: Urine osmolarity and risk of dialysis initiation in a chronic kidney disease cohort - a possible titration target? PLoS One 2014;9:e93226.

30 Shoham DA, Durazo-Arvizu R, Kramer H, Luke A, Vupputuri S, Kshirsagar A, et al: Sugary soda consumption and albuminuria: results from the national health and nutrition examination survey, 1999-2004. PLoS One 2008;3:e3431.

31 Roussel R, Fezeu L, Marre M, Velho G, Fumeron F, Jungers $\mathrm{P}$, et al: Comparison between copeptin and vasopressin in a population from the community and in people with chronic kidney disease. J Clin Endocrinol Metab 2014;99:4656-4663.

32 Cohen J: Mesoamerica's mystery killer. Science 2014;344:143-147.

33 Trabanino RG, Aguilar R, Silva CR, Mercado MO, Merino RL: [End-stage renal disease among patients in a referral hospital in El Salvador]. Rev Panam Salud Publica 2002;12: 202-216.

34 Ordunez P, Saenz C, Martinez R, Chapman E, Reveiz L, Becerra F: The epidemic of chronic kidney disease in central America. Lancet Glob Health 2014;2:e440-e441.

35 O'Donnell JK, Tobey M, Weiner DE, Stevens LA, Johnson S, Stringham P, et al: Prevalence of and risk factors for chronic kidney disease in rural Nicaragua. Nephrol Dial Transplant 2011;26:2798-2805.

36 Peraza S, Wesseling C, Aragon A, Leiva R, García-Trabanino RA, Torres C, et al: Decreased kidney function among agricultural workers in El Salvador. Am J Kidney Dis 2012; 59:531-540.

37 Wesseling C, Crowe J, Hogstedt C, Jakobsson K, Lucas R, Wegman DH; First International Research Workshop on the Mesoamerican Nephropathy: Resolving the enigma of the Mesoamerican nephropathy: a research workshop summary. Am J Kidney Dis 2014; 63:396-404

38 O'Donnell JK, Tobey M, Weiner DE, Stevens LA, Johnson S, Stringham P, et al: Prevalence of and risk factors for chronic kidney disease in rural Nicaragua. Nephrol Dial Transplant 2011;26:2798-2805.

39 Wijkström J, Leiva R, Elinder CG, Leiva S, Trujillo Z, Trujillo L, et al: Clinical and pathological characterization of Mesoamerican nephropathy: a new kidney disease in Central America. Am J Kidney Dis 2013;62:908-918.

40 Brooks DR, Ramirez-Rubio O, Amador JJ: CKD in Central America: a hot issue. Am J Kidney Dis 2012;59:481-484.

41 Johnson RJ, Rodriguez-Iturbe B, RoncalJimenez C, Lanaspa MA, Ishimoto T, Nakagawa T, et al: Hyperosmolarity drives hypertension and CKD - water and salt revisited. Nat Rev Nephrol 2014;10:415-420.

42 Weiner DE, McClean MD, Kaufman JS, Brooks DR: The Central American epidemic of CKD. Clin J Am Soc Nephrol 2013;8:504511.

43 Laws RL, Brooks DR, Amador JJ, Weiner DE, Kaufman JS, Ramírez-Rubio O, et al: Changes in kidney function among Nicaraguan sugarcane workers. Int J Occup Environ Health 2015;21:241-250.

44 Laws RL, Brooks DR, Amador JJ, Weiner DE, Kaufman JS, Ramírez-Rubio O, et al: Biomarkers of kidney injury among Nicaraguan sugarcane workers. Am J Kidney Dis 2016;67: 209-217.

45 Crowe J, Wesseling C, Solano BR, Umaña MP, Ramírez AR, Kjellstrom T, et al: Heat exposure in sugarcane harvesters in Costa Rica. Am J Ind Med 2013;56:1157-1164.

46 Solís-Zepeda G: Impacto de las medidas preventivas para evitar el deterioro de la función renal por el Síndrome de Golpe por Calor en trabajadores agrícolas del Ingenio San Antonio del Occidente de Nicaragua, Ciclo Agrícola 2005-2006. León, 2007.

47 Correa-Rotter R, Wesseling C, Johnson RJ: $\mathrm{CKD}$ of unknown origin in Central America: the case for a Mesoamerican nephropathy. Am J Kidney Dis 2014;63:506-520.

48 Roncal Jimenez CA, Ishimoto $\mathrm{T}$, Lanaspa MA, Rivard CJ, Nakagawa T, Ejaz AA, et al: Fructokinase activity mediates dehydrationinduced renal injury. Kidney Int 2014;86: 294-302.

49 Robey RB: Cyclical dehydration-induced renal injury and Mesoamerican nephropathy: as sweet by any other name? Kidney Int 2014; 86:226-229.

50 Machiraju RS, Yaradi K, Gowrishankar S, Edwards KL, Attaluri S, Miller F, Grollman AP: Epidemiology of Udhanam endemic nephropathy. J Am Soc Nephrol 2009;20:643A

51 Athuraliya NT, Abeysekera TD, Amerasinghe $\mathrm{PH}$, Kumarasiri R, Bandara P, Karunaratne U, et al: Uncertain etiologies of proteinuricchronic kidney disease in rural Sri Lanka. Kidney Int 2011;80:1212-1221.

52 Paula Santos U, Zanetta DM, Terra-Filho M Burdmann EA: Burnt sugarcane harvesting is associated with acute renal dysfunction. Kidney Int 2015;87:792-799.

53 Patnala K, Raju DSSK, Rachel KV: Climate change and chronic kidney disease. Asian J Pharm Clin Res 2014;7:53-57.

54 Hansen AL, Bi P, Ryan P, Nitschke M, Pisaniello $D$, Tucker G: The effect of heat waves on hospital admissions for renal disease in a temperate city of Australia. Int J Epidemiol 2008; 37:1359-1365.

55 Bobb JF, Obermeyer Z, Wang Y, Dominici F: Cause-specific risk of hospital admission related to extreme heat in older adults. JAMA 2014:312:2659-2667.

56 Barbieri A, Pinna C, Fruggeri L, Biagioni E, Campagna A: Heat wave in Italy and hyperthermia syndrome. South Med J 2006;99:829_ 831.

57 Bates DV: Why do older patients die in a heatwave? QJM 2005;98:840-841.
Hydration and CKD Progression:

A Critical Review of the Evidence
Am J Nephrol 2016;43:281-292

DOI: $10.1159 / 000445959$ 
58 Fletcher BA, Lin S, Fitzgerald EF, Hwang SA: Association of summer temperatures with hospital admissions for renal diseases in New York State: a case-crossover study. Am J Epidemiol 2012;175:907-916.

59 Clark WF, Sontrop JM, Huang SH, Gallo K, Moist L, House AA, et al: The chronic kidney disease water intake trial (WIT): results from the pilot randomised controlled trial. BMJ Open 2013;3:e003666.

60 Sontrop JM, Huang SH, Garg AX, Moist L, House AA, Gallo K, et al: Effect of increased water intake on plasma copeptin in patients with chronic kidney disease: results from a pilot randomised controlled trial. BMJ Open 2015;5:e008634.

61 Meijer E, Bakker SJ, Halbesma N, de Jong PE, Struck J, Gansevoort RT: Copeptin, a surrogate marker of vasopressin, is associated with microalbuminuria in a large population cohort. Kidney Int 2010;77:29-36.

62 Enhörning S, Bankir L, Bouby N, Struck J, Hedblad B, Persson M, et al: Copeptin, a marker of vasopressin, in abdominal obesity, diabetes and microalbuminuria: the prospective Malmö diet and cancer study cardiovascular cohort. Int J Obes (Lond) 2013;37:598-603.

63 Velho G, Bouby N, Hadjadj S, Matallah N, Mohammedi K, Fumeron F, et al: Plasma copeptin and renal outcomes in patients with type 2 diabetes and albuminuria. Diabetes Care 2013;36:3639-3645.

64 Boertien WE, Riphagen IJ, Drion I, Alkhalaf A, Bakker SJ, Groenier KH, et al: Copeptin, a surrogate marker for arginine vasopressin, is associated with declining glomerular filtration in patients with diabetes mellitus (ZODIAC-33). Diabetologia 2013;56:1680-1688.

65 Pearle MS, Goldfarb DS, Assimos DG, Curhan G, Denu-Ciocca CJ, Matlaga BR, et al: Medical management of kidney stones: AUA guideline. J Urol 2014;192:316-324.

66 Qaseem A, Dallas P, Forciea MA, Starkey M, Denberg TD; Clinical Guidelines Committee of the American College of Physicians: Dietary and pharmacologic management to prevent recurrent nephrolithiasis in adults: a clinical practice guideline from the American College of Physicians. Ann Intern Med 2014 161:659-667.

67 Cheungpasitporn W, Rossetti S, Friend K, Erickson SB, Lieske JC: Treatment effect, adherence, and safety of high fluid intake for the prevention of incident and recurrent kidney stones: a systematic review and meta-analysis. J Nephrol 2016;29:211-219.

68 Dawson $\mathrm{CH}$, Tomson CR: Kidney stone disease: pathophysiology, investigation and medical treatment. Clin Med (Lond) 2012;12: 467-471.

69 Shuster J, Jenkins A, Logan C, Barnett T, Riehle R, Zackson D, et al: Soft drink con- sumption and urinary stone recurrence: a randomized prevention trial. J Clin Epidemiol 1992;45:911-916.

70 Ferraro PM, Taylor EN, Gambaro G, Curhan GC: Soda and other beverages and the risk of kidney stones. Clin J Am Soc Nephrol 2013;8: 1389-1395.

71 Fox IH, Kelley WN: Studies on the mechanism of fructose-induced hyperuricemia in man. Metabolism 1972;21:713-721.

72 Nguyen NU, Dumoulin G, Henriet MT, Regnard J: Increase in urinary calcium and oxalate after fructose infusion. Horm Metab Res 1995;27:155-158.

73 Grantham JJ, Torres VE, Chapman AB Guay-Woodford LM, Bae KT, King BF Jr, et al: Volume progression in polycystic kidney disease. N Engl J Med 2006;354:21222130.

74 Chapman AB, Bost JE, Torres VE, GuayWoodford L, Bae KT, Landsittel D, et al: Kidney volume and functional outcomes in autosomal dominant polycystic kidney disease. Clin J Am Soc Nephrol 2012;7:479-486.

75 Igarashi P, Somlo S: Genetics and pathogenesis of polycystic kidney disease. J Am Soc Nephrol 2002;13:2384-2398.

76 Nagao S, Nishii K, Katsuyama M, Kurahashi $\mathrm{H}$, Marunouchi $\mathrm{T}$, Takahashi $\mathrm{H}$, et al: Increased water intake decreases progression of polycystic kidney disease in the PCK rat. J Am Soc Nephrol 2006;17:2220-2227.

77 Wang CJ, Creed C, Winklhofer FT, Grantham $\mathrm{JJ}$ : Water prescription in autosomal dominant polycystic kidney disease: a pilot study. Clin J Am Soc Nephrol 2011;6:192-197.

78 Torres VE, Bankir L, Grantham JJ: A case for water in the treatment of polycystic kidney disease. Clin J Am Soc Nephrol 2009;4:11401150.

79 Boertien WE, Meijer E, Zittema D, van Dijk MA, Rabelink TJ, Breuning MH, et al: Copeptin, a surrogate marker for vasopressin, is associated with kidney function decline in subjects with autosomal dominant polycystic kidney disease. Nephrol Dial Transplant 2012;27:4131-4137.

80 Higashihara E, Nutahara K, Tanbo M, Hara $\mathrm{H}$, Miyazaki I, Kobayashi K, et al: Does increased water intake prevent disease progression in autosomal dominant polycystic kidney disease? Nephrol Dial Transplant 2014; 29:1710-1719.

81 Chazot C, Wabel P, Chamney P, Moissl U, Wieskotten S, Wizemann V: Importance of normohydration for the long-term survival of haemodialysis patients. Nephrol Dial Transplant 2012;27:2404-2410.

82 London GM, Pannier B, Guerin AP, Blacher J, Marchais SJ, Darne B, et al: Alterations of left ventricular hypertrophy in and survival of patients receiving hemodialysis: follow-up of an interventional study. J Am Soc Nephrol 2001;12:2759-2767.

83 McIntyre CW, Burton JO, Selby NM, Leccisotti L, Korsheed S, Baker CS, et al: Hemodialysis-induced cardiac dysfunction is associated with an acute reduction in global and segmental myocardial blood flow. Clin J Am Soc Nephrol 2008;3:19-26.

84 Parfrey PS, Foley RN, Harnett JD, Kent GM, Murray DC, Barre PE: Outcome and risk factors for left ventricular disorders in chronic uraemia. Nephrol Dial Transplant 1996;11: 1277-1285.

85 Burton JO, Jefferies HJ, Selby NM, McIntyre CW: Hemodialysis-induced repetitive myocardial injury results in global and segmental reduction in systolic cardiac function. Clin J Am Soc Nephrol 2009;4:1925-1931.

86 Burton JO, Jefferies HJ, Selby NM, McIntyre $\mathrm{CW}$ : Hemodialysis-induced cardiac injury: determinants and associated outcomes. Clin I Am Soc Nephrol 2009;4:914-920.

87 I. NKF-K/DOQI clinical practice guidelines for hemodialysis adequacy: update 2000 . Am J Kidney Dis 2001;37(1 suppl 1):S7-S64.

88 Harada H, Nakamura M, Hotta K, Iwami D, Seki T, Togashi M, et al: Percentages of water, muscle, and bone decrease and lipid increases in early period after successful kidney transplantation: a body composition analysis. Transplant Proc 2012;44:672-675.

89 Meijer E, Bakker SJ, de Jong PE, Homan van der Heide JJ, van Son WJ, Struck J, et al: Copeptin, a surrogate marker of vasopressin, is associated with accelerated renal function decline in renal transplant recipients. Transplantation 2009;88:561-567.

90 Gordon EJ, Prohaska TR, Gallant MP, Sehgal AR, Strogatz D, Conti D, et al: Prevalence and determinants of physical activity and fluid intake in kidney transplant recipients. Clin Transplant 2010;24:E69-E81.

91 Gordon EJ, Prohaska TR, Gallant MP, Sehgal AR, Strogatz D, Yucel R, et al: Longitudinal analysis of physical activity, fluid intake, and graft function among kidney transplant recipients. Transpl Int 2009;22: 990-998.

92 Weber M, Berglund D, Reule S, Jackson S, Matas AJ, Ibrahim HN: Daily fluid intake and outcomes in kidney recipients: post hoc analysis from the randomized ABCAN trial. Clin Transplant 2015;29:261-267.

93 Kullgren KA, Scholl P, Kidwell KM, Hmiel SP: Using an interactive water bottle to target fluid adherence in pediatric kidney transplant recipients: a pilot study. Pediatr Transplant 2015;19:35-41.

94 Magpantay L, Ziai F, Oberbauer R, Haas M: The effect of fluid intake on chronic kidney transplant failure: a pilot study. J Ren Nutr 2011;21:499-505. 